\title{
Time-frequency analysis for concrete dam safety control: Correlation between the daily variation of structural response and air temperature
}

\author{
J. Mata ${ }^{\mathrm{a}, *}$, A. Tavares de Castro ${ }^{\mathrm{a}}$, J. Sá da Costa ${ }^{\mathrm{b}}$ \\ ${ }^{a}$ Concrete Dams Department, National Laboratory for Civil Engineering, Av. do Brasil 101, 1700-066 Lisbon, Portugal \\ ${ }^{\mathrm{b}}$ IST, Technical University of Lisbon, Av. Rovisco Pais 1, 1049-001 Lisbon, Portugal
}

\section{A R T I C L E I N F O}

\section{Article history:}

Received 22 June 2012

Revised 29 November 2012

Accepted 1 December 2012

Available online 11 January 2013

\section{Keywords:}

Structural health monitoring

Concrete dam behaviour

Spectral analysis

Short time fourier transform

Quantitative models

Automated data acquisition system

\begin{abstract}
A B S T R A C T
The purpose of this research work is to identify the effect of the daily variation of the air temperature on the structural response of a concrete dam. It is intended to obtain a better knowledge about structural behaviour of concrete dams. In current day to day activities, quantitative interpretation models are used for the assessment of structural dam behaviour of concrete dams. Most models ignore the temperature effect of a wave with a daily variation. However, in dams with automated data acquisition systems this daily effect can be used to anticipate the detection of abnormal behaviour.

In this paper, the Short Time Fourier Transform analysis of the residuals is used, obtained by the quantitative interpretation models and measurement data, to identify the signature that the daily variation of the air temperature has on the structural behaviour of a concrete dam. A case study is presented based on the analysis of a horizontal displacement measured on a pendulum, in the Alto Lindoso concrete dam. As a result, the relation between magnitudes of daily variations of the horizontal displacement analysed and the air temperature was defined. The relation obtained can be used to assess if there is alterations or not in the dam response to short period loads corresponding to the daily variations analysed.
\end{abstract}

(c) 2012 Elsevier Ltd. All rights reserved.

\section{Introduction}

Structural health monitoring of a concrete dam is based on visual inspection of the structure and on the analysis of monitoring data with the purpose of, as early as possible, identifying eventual anomalous behaviour to eliminate or to minimise its effects. In recent years, automated monitoring systems have been used in the structural health monitoring of concrete dams due to the capability of measuring the structural response and the main loads at dams with/without access with the desired frequency $[1,2]$.

The interpretation of the observed dam behaviour data is based on the identification of correlations between the loads, the structural properties, including properties of materials, and the structural responses [3-9]. The structural response observed is the consequence of the combination of the effects due to the main loads, mainly the hydrostatic load and the temperature variations.

The observed structural responses, like displacements, are compared with predicted values obtained by statistical models, such as quantitative interpretation models, or by numerical models, such as finite element models. The quantitative interpretation models, fitted with measured data, are valid within the domain of

\footnotetext{
* Corresponding author. Tel.: +351 218443372; fax: +351 218443026.

E-mail addresses: jmata@lnec.pt (J. Mata), tcastro@lnec.pt (A. Tavares de Castro), sadacosta@dem.ist.utl.pt (J. Sá da Costa).
}

measured data. The difference between the observed values and the predicted values obtained by models are the residuals. Besides anomalous phenomena, the residuals contain information related to errors (measurements and model) and other unknown effects.

This study shows that relevant information can be extracted from the residuals with a time-frequency analysis. In concrete dams the acting loads are non-stationary, as well as the residuals from the behaviour models. Therefore care needs to be taken when performing a time-frequency analysis of the data in these cases.

The main information obtained in a time-frequency analysis is related to the detection of the dominant frequencies along time. Three main methods are available to detect dominant frequencies in non-stationary signals, namely the Short Time Fourier Transform (STFT), the Wigner-Ville distribution and the Wavelet transform [10-13].

The STFT is the most widely used method for studying nonstationary signals in structural engineering [14-19]. The basic idea of the STFT method is to break up the signal into small time segments, and to perform Fourier analyses of each time segment to ascertain the frequencies that exist in it. For each time period a different spectrum is obtained and the totality of these spectra give the time-frequency distribution.

The new idea proposed in this study is to use STFT to identify the influence of the daily variation of air temperature on the horizontal displacement of concrete dams and track its variation as a function of time, which can be used to validate new observations. 